\title{
Knowledge, Attitude and Practice of Infection Prevention Measures among Health Care Workers in Wolaitta Sodo Otona Teaching and Referral Hospital
}

Hussen $\mathrm{SH}^{1^{*}}$, Estifanos $\mathrm{WM}^{2}$, Melese $\mathrm{ES}^{3}$ and Moga $\mathrm{FE}^{2}$

${ }^{1}$ Department of Reproductive Health, Arba Minch University, Arba Minch, Ethiopia

${ }^{2}$ Department of Nursing, Arba Minch University, Arba Minch, Ethiopia

${ }^{3}$ Department of Statistics, Arba Minch University, Arba Minch, Ethiopia

*Corresponding author: Hussen SH, Department of Reproductive Health, Arba Minch University, Arba Minch, Ethiopia, Tel: 251468814986; E-mail: sultanhussn@gmail.com

Received date: July 03, 2017; Accepted date: July 22, 2017; Published date: July 30, 2017

Copyright: ( 2017 Hussen SH, et al. This is an open-access article distributed under the terms of the Creative Commons Attribution License, which permits unrestricted use, distribution, and reproduction in any medium, provided the original author and source are credited

\begin{abstract}
Background: Infection prevention is a systematic effort or process of placing barrier between susceptible host and the microorganisms. It also refers to all policies, procedures and activities which aim to prevent or minimize the risk of transmission of infectious disease at health care facility. As far as we know there is no similar study has been done on Wolaitta Sodo teaching and referral hospital, so this study is aim to assess Knowledge, Attitude and Practice on infection prevention and control measures among health professionals.
\end{abstract}

Objectives: The main objective of this study is to assess knowledge, attitude and practice of infection prevention measures among health care workers in Wolaitta Sodo teaching and referral hospital, SNNPR, Ethiopia, in March 2017.

Methods: The study was conducted at Wolaitta Sodo teaching and referral hospital, South East Ethiopia and Cross-sectional study design was conducted. From the total of 282 respondents, two hundred seventy one were responded to the study. Self-administered questionnaire were used to collect data. Data were entered in to SPSS version 20 for analysis. Both bivariable and multivariable variable logistic regression were done and for variables which had P-value less than 0.25 in bivariable analysis were inserted in to multivariable logistic regression. Then the variables with $p$-value of less than 0.05 were considered as predictors of the outcome variable. Data were checked for consistency and completeness. Letter of support was obtained from department of nursing and verbal consent was obtained from the institution and all participants.

Results: From the total 282 health care workers (HCWs), $271 \mathrm{HCWs}$ were responded with response rate of $95.7 \%$. Among the respondents $253(93.4 \%)$ have good attitude towards infection prevention and $18(6.6 \%)$ of the respondents have negative attitude towards infection Prevention. $269(99.3 \%)$ of HCWs have good knowledge towards infection prevention and $2(0.7 \%)$ have poor knowledge and $164(60.5 \%)$ of HCWs have good practice towards infection prevention and the remaining 107 (39.5\%) of health care workers had poor practice. According to this study sex, working in different departments and receiving formal training has significant association with infection prevention practice but educational status, work experience and job title has no significant association with infection prevention practice.

Conclusion: Majority of health care workers' knowledge and attitude toward infection prevention in Wolaitta Sodo Otona teaching and referral hospital were good and safe enough, but practice of health care workers towards infection control were not sufficient enough. Wolaitta Zone health bureau should monitor and supervise health care workers towards infection prevention practice and control measures with the routine services through preparing and introducing health care workers infection prevention guidelines, protocol, rules, regulation and opportunities to promote the desired team sprit at all health facility levels are recommended.

Keywords: Knowledge; Attitude; Practice; Infection prevention measure; Wolaita Sodo

\section{Introduction}

Infection prevention is a systematic effort or process of placing barrier between susceptible host and the microorganisms [1]. Infection control also refers to all policies, procedures and activities which aim to prevent or minimize the risk of transmission of infectious disease at health care facility [2]. Reports indicate that standard precautions are effective in preventing both occupational exposure incident and associated infections [3].

Health care-associated infection is "An infection occurring in a patient during the process of care in a hospital or other healthcare facility which was not present or incubating at the time of admission." This includes infections acquired in the hospital but appearing after discharge, and also occupational infections among staff of the facility [4]. 
The endemic burden of health care-associated infection is also significantly higher in low- and middle-income than in high-income countries, in particular in patients admitted to intensive care units and in neonates [5].

Despite the availability of low-cost interventions for infection prevention and control, the compliance with standard infection control practices remains very low, particularly in low-income and middle income countries [6].

According to the fact sheet of World Health Organization (WHO) there are several factors which can cause health care-associated infections. Among this Prolonged and inappropriate use of devices and antibiotics, high-risk and sophisticated procedures, immunesuppression and other severe underlying patient conditions and insufficient application of standard precautions are some of factors which present regardless of the resources available [5].

To improve the control and prevention of infections in countries with limited resources, a multi-facet approach is needed that is based on improved healthcare structures, increased knowledge, effective guidelines, behavioral changes, attitude adjustment, better and efficient use of existing resources, as well as international cooperation [7].

Even though, some studies have focused on knowledge of and compliance with standard precautions, hand washing, knowledge and practice of infection control among hospital staff regardless of focusing in attitude. The information that has been generated on health care workers in Wolaitta Sodo Otona teaching and referral hospital about infection prevention measure is limited. Therefore, this study aimed to assess the knowledge, attitude and practice of infection prevention among all health care workers in Wolaitta Sodo Otona teaching and referral hospital.

\section{Materials and Methods}

\section{Study setting}

This institutional based cross study was conducted from March 1st to March 15th, 2017 in Wolaitta Sodo Otona hospital, which is one of the teaching and referral hospitals in SNNPR, located in Wolaitta Zone, Ethiopia with distance of $378 \mathrm{~km}$ South from Addis Ababa and $125 \mathrm{~km}$ distance from regional city Hawassa. Wolaittigna is spoken as a first language by $96.82 \%$ of the inhabitants. In Wolaitta Sodo town there are one governmental referral and one private hospital, three health centers, seven health posts and thirty private clinics. In Otona hospital there are 282 health care workers in total among them 52 were doctors, 113 were nurses of all type, 21 were laboratory workers and 96 were others such as pharmacy, technologists, radiologists and the likes.

\section{Sample size and sampling procedure}

In this study the sample size was calculated by using single population proportion formula based on the following assumption: Based on the finding from previous study, $76.3 \%$ of health care workers has good practice in the study in west Ethiopia in Mizan Aman hospital on infection prevention [8], expecting 5\% margin of error (d) and confidence level of 95\%, the total of 280 individuals were calculated as sample size. Since the calculated sample size and the HCWs in the hospital are similar in numbers, all HCWs were included in this study.

\section{Data collection}

Data were collected from study participants using self-administered questionnaire. After reviewing of the relevant literature, the data collection tools were developed, as appropriate to address the study objectives. Five percent of total sample respondents were interviewed during the pre-test in another health institution. After this, the questionnaires were edited accordingly, and after adapting the final version of the questionnaire, the questionnaire was distributed for each participant in the form of hard copy.

\section{Data processing and analysis}

The completeness and consistency of the data were checked, coded and double entered into Epi-Data 3.1. The data were exported to Statistical Package for the Social Sciences (SPSS) version 20 (IBM Corporation, Armonk, NY, USA) statistical soft-wares for further analysis. The analysis and modeling were conducted in several steps.

First, simple descriptive statistics such as a frequency distribution and percentages were performed to describe the characteristics of the study participant. At the second step, a bi-variable logistic model analysis was performed for each independent factor and outcome of interest to identify independent predictors. Upon the completion of the bivariable analysis, variables with a $\mathrm{P}$-value $<0.25$ were selected for the multivariable analysis to control for confounding and interaction effect. Once the variables were identified, multivariable analysis was performed by enter method.

To decide whether or not a variable is significant, the P-value associated with each parameter was estimated using the $\mathrm{P}$-value $<0.05$ as a cut-off point. The crude and adjusted odd ratios together with their corresponding 95\% confidence intervals were computed and interpreted accordingly.

\section{Ethical consideration}

A letter of clearance was obtained from Arba Minch University, College of Medicine and Health Science. After the letter has received we have disseminated it to Wolaitta zone health bureau, the study area health institution and other concerned bodies. A letter of approval was found from Wolaitta zone health bureau. Data was collected after explaining the rights and responsibilities of giving information and the purpose of the study to respondents and ascertain their confidentiality by explaining that no data were disclosed as an individual rather disseminated at community and health institution level in general. Finally informed consent was obtained from respondents, telling that they have the right not to answers the questions.

\section{Results and Discussion}

\section{Socio demographic characteristics}

A total of $282 \mathrm{HCWs}$ with response rate of (95.7\%) were found to complete and included in analysis. Among 271 respondents 156 (57.6\%) were males and $115(42.4 \%)$ were females. From the study participants, 39 (14.4\%) of HCWs were less than 25 years old and 68 (25.1\%) were in age group of $25-29$ years and $5(1.8 \%)$ were range in age group of above $>44$ years. Concerning the professional categories of respondents $111(41 \%)$ were nurses, $50(18.5 \%)$ were physicians and 99 (36.5\%) were other health professionals. One hundred five (38.7\%) of the respondents were professional with service year of less than five years and $113(41.7 .7 \%)$ between 5-10 years (Table 1). 
Citation: Hussen SH, Estifanos WM, Melese ES, Moga FE (2017) Knowledge, Attitude and Practice of Infection Prevention Measures among Health Care Workers in Wolaitta Sodo Otona Teaching and Referral Hospital. J Nurs Care 6: 416. doi:10.4172/2167-1168.1000416

Page 3 of 7

\begin{tabular}{|c|c|c|}
\hline Variables & Classification & Frequency (\%) \\
\hline \multirow[t]{6}{*}{ Age in years } & $<25$ & $39(14.4 \%)$ \\
\hline & $25-29$ & $68(25.1 \%)$ \\
\hline & $30-34$ & $83(30.6 \%)$ \\
\hline & $35-39$ & $56(20.7 \%)$ \\
\hline & $40-44$ & $20(7.4 \%)$ \\
\hline & $>44$ & $5(1.8 \%)$ \\
\hline \multirow[t]{2}{*}{ Sex of respondent } & Male & $156(57.6 \%)$ \\
\hline & Female & $131(48.3 \%)$ \\
\hline \multirow[t]{5}{*}{ Department } & Medical & $41(15.1 \%)$ \\
\hline & Surgical & $55(20.3 \%)$ \\
\hline & Obs/gyni & $40(14.8 \%)$ \\
\hline & Pediatrics & $40(14.8 \%)$ \\
\hline & Others & $95(35.1 \%)$ \\
\hline \multirow[t]{3}{*}{ Professions of respondents } & Physician & $50(18.5 \%)$ \\
\hline & Nurses & $111(41 \%)$ \\
\hline & Others & $99(36.5 \%)$ \\
\hline \multirow[t]{3}{*}{ Educational status of respondents } & Diploma & $124(45.8 \%)$ \\
\hline & Bsc & $85(31.4 \%)$ \\
\hline & Others & $62(22.9 \%)$ \\
\hline \multirow[t]{3}{*}{ Service years } & $<5$ & $105(38.7 \%)$ \\
\hline & 05-Oct & $113(41.7 \%)$ \\
\hline & $>10$ & $53(19.6 \%)$ \\
\hline \multirow[t]{3}{*}{ Marital status } & Unmarried & $82(30.2 \%)$ \\
\hline & Married & $181(66.8 \%)$ \\
\hline & Others & $8(9.2 \%)$ \\
\hline
\end{tabular}

\section{Knowledge on infection prevention measures}

All of the respondents (271) knew the safety precautions for disposal of needles, syringes and the risk of nosocomial infections and 267 (98.5\%) of the respondents were aware of for recommended guidelines for hand hygiene with alcohol based formulations. Among the respondents $264(97.4 \%)$ were received training in hand hygiene and standard precautions.

From the respondents 250 (92.3\%) know the impact of HCAIs in clinical outcome and $255(94.1 \%)$ of the respondents knew the effectiveness of hand washing in preventing health care related infections. From the respondents 209 (77.1\%) knew when to perform hand washing and 265 (97.8\%) knew the transmission mode of nosocomial infections and also $269(99.3 \%)$ of the respondents knew as infections can be transmitted through contact with blood and body fluids.

Among the respondents 252 (93\%) knew the effectiveness of standard precautions and 149 (55\%) not knew when to use glove. Two hundred two $(74.5 \%)$ of the respondents knew the objective of standard precautions and $246(90.8)$ knew the mechanism of bacteria and virus spread and $265(97.8 \%)$ of knew what to do in the room with TB patients.

In general 269 (99.3\%) of HCWs have good knowledge towards infection prevention and control measures and $2(0.7 \%)$ have poor knowledge (Figure 1 and Table 2).

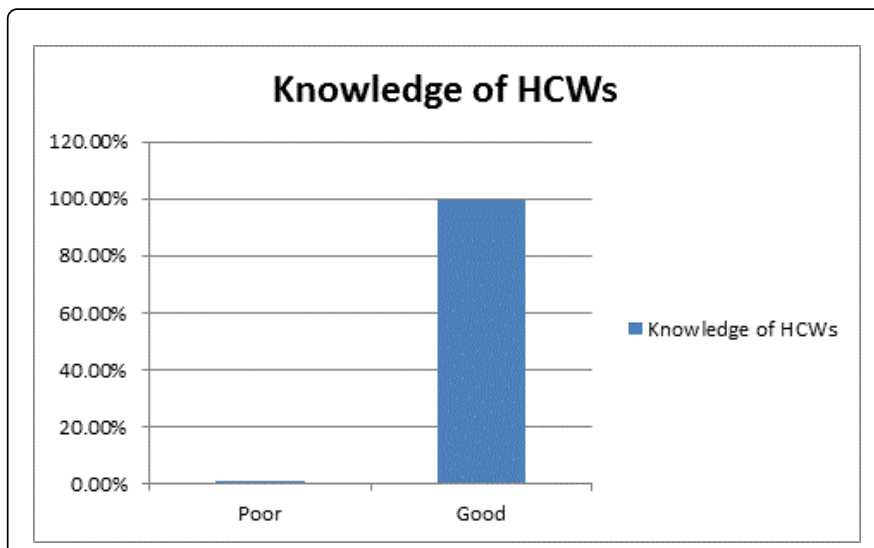

Figure 1: Knowledge on infection prevention measures of HCWs, Wolaitta Sodo Otona teaching and referral hospital, 2017.

Table 1: Socio-demographic characteristics of HCW's, Wolaitta Sodo teaching and referral hospital, 2017.

\begin{tabular}{|l|l|l|}
\hline No. & Variables & Frequency (\%) \\
\hline 1 & $\begin{array}{l}\text { Know about safety precautions for disposal of needles syringes and any wastes precautions for disposal of needles } \\
\text { syringes and any wastes }\end{array}$ & $271(100 \%)$ \\
\hline 2 & Aware of recommended guide lines for hand hygiene & $267(98.5 \%)$ \\
\hline 3 & Is there infection control team? & $264(97.4 \%)$ \\
\hline 4 & Did you receive training in hand hygiene and standard precautions? & $264(97.4 \%)$ \\
\hline 5 & Is there a system for reporting accidental exposure to blood and body fluids? & $264(97.4 \%)$ \\
\hline 6 & Do you know the impact of HCAls in clinical outcomes? & $250(92.3 \%)$ \\
\hline
\end{tabular}


Citation: Hussen SH, Estifanos WM, Melese ES, Moga FE (2017) Knowledge, Attitude and Practice of Infection Prevention Measures among Health Care Workers in Wolaitta Sodo Otona Teaching and Referral Hospital. J Nurs Care 6: 416. doi:10.4172/2167-1168.1000416

Page 4 of 7

\begin{tabular}{|l|l|l|}
\hline 7 & Do you know the effectiveness of hand washing in preventing HCAls? & $255(94.1 \%)$ \\
\hline 8 & Do you know when to perform hand washing? & $209(77.1 \%)$ \\
\hline 9 & Do you know nosocomial infections can be transmitted through medical equipment's? & $265(97.8 \%)$ \\
\hline 10 & Do you know nosocomial infections can be transmitted through blood and body fluid contamination? & $269(99.3 \%)$ \\
\hline 11 & Do you know when to use standard precautions? & $252(93 \%)$ \\
\hline 12 & Do you think glove is effective substitute for hand washing? & $149(55 \%)$ \\
\hline 13 & Do you know the objective of standard precautions? & $202(74.5 \%)$ \\
\hline 14 & Do you know by what mechanism bacteria and virus spread through can? & $246(90.8 \%)$ \\
\hline 15 & Do you know what to do in room with TB patients to prevent the spread? & $265(97.8 \%)$ \\
\hline
\end{tabular}

Table 2: knowledge on infection prevention measures of HCWs, Wolaitta Sodo Otona teaching and referral hospital, 2017.

\section{Attitude on infection prevention and control measures}

Out of 271 study participants 251 (92.6\%) of HCWs had positive attitude (agree and strongly agree) towards that every patient should be asked for detail if they have any signs and symptoms of infection and $20(7.4 \%)$ had negative (disagree, neutral and strongly disagree). From the total respondents 239 (88.2\%) had positive attitude (agree and strongly agree) that every patient should be voluntarily counselled and tested for HIV/AIDs to know their status and 32 (11.8\%) disagree, neutral, strongly disagree to advice every patient about VCT.
Among 271 study participants 251 (92.6\%) tell coughing patients to follow cough hygiene procedures such as using masks, covering mouth while coughing and sneezing and 20 (7.4\%)had negative attitude (disagree, neutral, and strongly disagree). From the total participants $262(96.7 \%)$ had positive (agree and strongly agree) that opening windows and doors of the ward is important to make the ward ventilated and $9(3.3 \%)$ of the respondents had negative (disagree, neutral and strongly disagree) to open windows and doors (Table 3).

\begin{tabular}{|c|c|c|c|c|c|c|}
\hline No. & Variable & & & Cate & & \\
\hline & & $\begin{array}{l}\text { Strongly } \\
\text { disagree }\end{array}$ & Disagree & Neutral & Agree & Strongly agree \\
\hline & & Freq. (\%) & Freq.(\%) & Freq. (\%) & Freq. (\%) & Freq. (\%) \\
\hline 1 & $\begin{array}{l}\text { I feel comfortable asking every patient if they have any } \\
\text { symptoms of infection }\end{array}$ & $1(0.4)$ & $12(4.4 \%)$ & $7(2.6 \%)$ & $102(37.6 \%)$ & $149(55 \%)$ \\
\hline 2 & Advising every patient to accept VCT & $4(1.5 \%)$ & $9(3.3 \%)$ & $19(7 \%)$ & $134(49.9 \%)$ & $105(38.7 \%)$ \\
\hline 3 & $\begin{array}{l}\text { Feeling comfortable to tell coughing patients to follow cough } \\
\text { hygiene procedures }\end{array}$ & $1(0.4 \%)$ & $12(4.8 \%)$ & $6(2.2 \%)$ & $152(56.1 \%)$ & $99(36.5 \%)$ \\
\hline 4 & Ventilating the ward by opening windows and doors & $1(0.4)$ & $3(1.1 \%)$ & $5(1.8 \%)$ & $127(46.9 \%)$ & $135(49.8 \%)$ \\
\hline 5 & Using PPE & $0(0 \%)$ & $6(2.2 \%)$ & $4(1.5 \%)$ & $128(47.2 \%)$ & $133(49.1 \%)$ \\
\hline 6 & Washing hands before and after contact with patients & $2(0.7 \%)$ & $9(3.3 \%)$ & $5(1.8 \%)$ & $107(39.5 \%)$ & $148(54.06 \%)$ \\
\hline 7 & Do you believe PPE protect HCWs from infection & $0(0 \%)$ & $4(1.1 \%)$ & $10(3.7 \%)$ & $136(50.2 \%)$ & $121(44.6 \%)$ \\
\hline 8 & $\begin{array}{l}\text { Do you agree that in the absence of universal precaution } \\
\text { hospital facilities can be the source of infection }\end{array}$ & $1(0.4 \%)$ & $4(1.1 \%)$ & $11(4.1 \%)$ & $148(54.6 \%)$ & $107(39.5 \%)$ \\
\hline 9 & Do you believe needles should be recapped after use & $24(8.9 \%)$ & $27(10 \%)$ & $11(4.1 \%)$ & $121(44.6 \%)$ & $88(32.5 \%)$ \\
\hline 10 & $\begin{array}{l}\text { Do you believe that nosocomial infection can pose serious } \\
\text { outcome }\end{array}$ & $1(0.4 \%)$ & $10(3.7 \%)$ & $17(6.3 \%)$ & $130(48 \%)$ & $113(41.7 \%)$ \\
\hline 11 & $\begin{array}{l}\text { Do you agree that recapping is the cause for needle prick } \\
\text { injury }\end{array}$ & $5(1.8 \%)$ & $47(17.3 \%)$ & $29(10.7 \%)$ & $109(40.2 \%)$ & $81(29.9 \%)$ \\
\hline
\end{tabular}


Citation: Hussen SH, Estifanos WM, Melese ES, Moga FE (2017) Knowledge, Attitude and Practice of Infection Prevention Measures among Health Care Workers in Wolaitta Sodo Otona Teaching and Referral Hospital. J Nurs Care 6: 416. doi:10.4172/2167-1168.1000416

Page 5 of 7

\begin{tabular}{|l|l|l|l|l|l|l|}
12 & $\begin{array}{l}\text { Do you believe separating active TB patients from other } \\
\text { patients is an effective strategy for trans. of TB }\end{array}$ & $3(11 \%)$ & $9(3.3 \%)$ & $8(3 \%)$ & $102(37.6 \%)$ & $149(55 \%)$
\end{tabular}

Table 3: Attitude of HCWS on infection prevention measures in WSTRH in 2017.

\section{Practice towards infection prevention measures}

Among the respondents 22 (8.1\%) follows recommended guide lines for use of alcohol based solutions and other antiseptics after lifting and moving a patient and $121(44.6 \%)$ recaps needle after use. From the total respondents $261(96.3 \%)$ discard used needles and other wastes in to their container and $47(17.3 \%)$ of the participants of the study removes rings and bracelets and watches before beginning hand hygiene and also 261 (96.3\%) dispose sharps separately from other wastes. In general $164(60.5 \%)$ of HCWs have good practice towards infection prevention and control measures and the remaining 107 (39.5\%) of health care workers have poor practice (Table 4 ).

\begin{tabular}{|l|l|l|}
\hline No. & Variables & Frequency (\%) \\
\hline 1 & & Yes \\
\hline 2 & Do you follow recommended guide lines for use of alcohol and other antiseptics after lifting and moving patient? & $22(8.1 \%)$ \\
\hline 3 & Do you recap used needle? & $121(44.6 \%)$ \\
\hline 4 & Do you discard wastes immediately in to their container? & $261(96.3 \%)$ \\
\hline 5 & Do you remove rings and bracelets before beginning hand hygiene? & $47(17.3 \%) 17.3$ \\
\hline 6 & Do you have written guide line on waste disposal? & $267(98.5 \%)$ \\
\hline 7 & If yes do all staffs apply the guide line? & $270(99.6 \%)$ \\
\hline 8 & Do you have isolation criteria for those who are admitted with highly contagious diseases? & $125(46.1 \%) 99.6$ \\
\hline 9 & Do you discard sharp materials separately from other wastes? & $261(96.3 \%)$ \\
\hline
\end{tabular}

Table 4: Practice of HCWs on infection prevention in WSTRH in 2017.

\section{Factors associated with practice on infection prevention measure in WSTRH}

According to this study sex and working in different department has significant association with infection prevention practice but educational status, work experience and job title has no significant association with infection prevention practice (Table 5).

\begin{tabular}{|c|c|c|c|c|c|}
\hline Variable & Category & P-value & COR $(95 \% \mathrm{Cl})$ & P-value & AOR $(95 \% \mathrm{Cl})$ \\
\hline \multirow[t]{2}{*}{ Sex } & Male & 0.016 & $1.833(1.118-3.007)$ & 0.005 & $0.379(0.193-0.743)$ \\
\hline & Female (R) & & 1 & & \\
\hline \multirow[t]{5}{*}{ Department } & Medical (R) & & 1 & & \\
\hline & Surgical & 0 & $11.054(4.391-27.829)$ & 0 & $0.076(0.028-0.206)$ \\
\hline & Oby/gyn & 0 & $7.353(3.439-15.723)$ & 0 & $0.127(0.054-0.03)$ \\
\hline & Pediatrics & 0.001 & $3.739(1.748-8.232)$ & 0.001 & $0.17(0.06-0.48)$ \\
\hline & Other & 0 & $12.897(4.881-34.073)$ & 0 & $0.073(0.026-0.203)$ \\
\hline \multirow[t]{3}{*}{ Educational status } & Diploma (R) & & 1 & & \\
\hline & B.Sc. & 0.001 & $0.289(0.138-0.607)$ & 0.114 & $1.933(0.851-4.532)$ \\
\hline & Other & 0 & $0.211(0.097-0.459)$ & 0.307 & $1.654(0.63-4.344)$ \\
\hline Receiving formal training & Yes & & 1 & & \\
\hline
\end{tabular}




\begin{tabular}{|l|l|l|l|l|l|}
\hline & No & 0.037 & $0.103(0.012-0.87)$ & 0.037 & $9.683(1.49-81.605$ \\
\hline
\end{tabular}

Table 5: Bivariable and multivariable analysis of factors affecting infection prevention practice among HCWs in Wolaitta Sodo, Otona teaching and referral hospital in 2017.

From this study male health care workers were $62 \%$ less likely to practice infection prevention when compared with female health care workers $(\mathrm{AOR}=0.379(0.193-0.743))$. Health care workers who work in surgical ward were $92 \%$ less likely to practice infection prevention when compared with HCWs in medical ward (AOR $=0.076$ (0.028-0.206)) and HCWs in Obs/gyn were $87 \%$ less likely to practice infection prevention $(\mathrm{AOR}=0.127 \quad(0.054-0.03))$ also HCWs in pediatrics ward were $87 \%$ less practice infection prevention $(\mathrm{AOR}=0.17(0.06-0.48))$ and the remaining health care workers from other departments were $92 \%$ less likely to practice infection prevention $(\mathrm{AOR}=0.073(0.026-0.203))$. According to this study health care workers not received training on infection prevention were nearly 10 times more likely to practice infection prevention.

\section{Discussion}

This study revealed that $99.3 \%$ of health care workers had good knowledge and $0.7 \%$ of them had poor knowledge. This study finding is high when compared with finding from Health institutions from Baghdad city which revealed that $69 \%$ of health care workers had poor knowledge and $31 \%$ had good knowledge [9], teaching hospital of Zabol which revealed that $43 \%$ of the participants had poor knowledge and the remaining $57 \%$ had good knowledge [10].

This study finding is also higher when compared with finding from Palestine hospital which revealed $53.9 \%$ of the study participants had good knowledge [11]. This study finding is almost similar with finding from Dessie referral hospital which revealed $95.19 \%$ had good knowledge and 4.81 of the health care workers had poor knowledge [12] and also higher than finding from Amhara regional state referral hospital which showed $>50 \%$ of the study participants had poor knowledge on infection prevention and control [12] and Bahir-dar city health institutions which revealed $84.5 \%$ of health care workers had good knowledge [13].This discrepancy may be due to the difference in setting, in sample size and having of training, characteristics of the study participants and difference in health related policies and guide lines.

This study showed that $93.4 \%$ of health care workers had good attitude and $6.6 \%$ of health care workers had poor attitude towards infection prevention. This finding is higher when compared with finding from teaching hospital of Zabol which revealed 33\% of HCWs had good attitude [10]. And also higher from the study result conducted from health institutions from Bahir-dar city which revealed $55.6 \%$ of health care workers had good attitude [13].This difference may be due to variation in setting of the study and it also may be due to difference in awareness of health care workers.

This study showed that $60.5 \%$ of health care workers had good practice and $39.5 \%$ of health care workers had poor practice on infection prevention and control measures. The finding from this study is higher when compared with finding from Zabol teaching hospital which showed $34 \%$ of the study participants had good practice [10]. This study finding is also higher than finding from Amhara regional state referral hospital which revealed that $>50 \%$ of the study participants had poor practice on infection prevention and control
[12].This variation is may be due to difference in sample size, difference in participant's characteristics and due training and infection prevention guideline availability.

This study finding is almost similar with finding from health institutions of Bahir-dar city which showed $54.2 \%$ of study participants had good practice towards infection prevention and control measures [13].

This study finding is lower when compared with finding from Dessie referral hospital which revealed $87.5 \%$ of the study participants had good practice [13]. Also this study finding is lower when compared with finding from Palestine hospital which revealed $91.1 \%$ of the study participants had good practice towards infection prevention and control measures [11]. This variation is may be due to difference in sample size, difference in setting and population characteristics and it may be due to not following recommended infection prevention guide lines.

This study revealed that there is significant statistical association in sex of HCWs, working in different units or wards and there also statistically negative association in having of training with infection prevention practice. But the study in Amhara regional state referral hospital showed that there is significant statistical association in age of HCWS, service year and educational status [12]. Also the study conducted in Palestine hospital revealed that there is no statistically significant association between age, years of experience and having of training this discrepancy may be due to difference in setting and population characteristics

\section{Conclusion}

Majority of health care workers' knowledge and attitude toward infection prevention and control measures in Wolaitta Sodo Otona teaching and referral hospital were good and safe enough but practice of health care workers towards infection control were not sufficient. Variables such as, receiving formal training and working in different department has association with infection prevention practice but educational status, work experience and job title has no significant association with infection prevention practice.

\section{Recommendations}

Based on the study finding the following recommendations are forwarded:

Otona teaching and referral hospital should encourage health care workers on application of written guide lines on use of personal protective equipment's encourage health care workers to use personal protective equipment's.

Otona teaching and referral hospital health care workers should apply written guide lines toward infection prevention and control measures responsibly. 
Citation: Hussen SH, Estifanos WM, Melese ES, Moga FE (2017) Knowledge, Attitude and Practice of Infection Prevention Measures among Health Care Workers in Wolaitta Sodo Otona Teaching and Referral Hospital. J Nurs Care 6: 416. doi:10.4172/2167-1168.1000416

Page 7 of 7

The focal person of each department (ward) should follow health care workers closely and should take appropriate measure on HCWs who fails to practice as per guideline and protocol.

Otona teaching and referral hospital administrative bodies should focus on and supervise male health care workers.

Wolaitta Zone health bureau should monitor and supervise health care workers towards infection prevention practice and control measures with the routine services through provision of training and preparing and introducing health care workers infection prevention guidelines, protocol, rules, regulation and opportunities to promote the desired team sprit at all health facility levels are recommended.

\section{Competing Interest}

The authors declare that they have no competing interest.

\section{Authors' Contributions}

SH, EM, WE and FM conceived and designed the study, developed data collection instruments and supervised data collection. SH, WE and FM participated in the testing and finalization of the data collection instruments and coordinated study progress. SH, WE and FM performed the statistical analysis, $\mathrm{SH}$ and EM wrote all versions of the manuscript. All authors read and approved the final manuscript.

\section{Acknowledgement}

Our warmest gratitude goes to Arba Minch University for all support and commitment for this research. The authors are great full to all health care professional who participated in the study.

\section{References}

1. Tietjen Let (2011) Infection prevention guideline for health care facilities with limited resource. JHPHIEGO.
2. WHO, Western Pacific Region.

3. Admasu TE, Edward AS, Limndsay ME (2013) Infection control knowledge, attitude and practice among health workers in Addis Ababa, Ethiopia. Infect Control Hosp Epidemiol 34: 1289-1296.

4. Benedetta AL (2017) Infection control in developing nations. A practical guide. WHO 2002.

5. WHO (2017) Health care-associated infections FACT SHEET. Patient safety a world alliance for safer health care.

6. WHO (2017) Infection prevention and control in health care: time for collaborative action. Technical paper, Fifty-seventh Session.

7. Emine AL, Hakan L, Mehmet D, Andreas V (2011) Infection control practice in countries with limited resources. Ann Clin Microbiol Antimicrob 10: 36

8. Yakob E, Lamaro T, Henok A (2017) Knowledge, attitude and practice towards infection control measures among Mizan-Aman General Hospital Workers, South West Ethiopia. J Community Med Health Educ 5: 370 .

9. Mohammed BA, Jaffar AJ (2017) Assessment of nurse's knowledge about nosocomial infection at hospitals in Baghdad City. Journal of Kufa for Nursing Science 4

10. Hamed S, Abbas B, Nosratollah M, Ebrahim E (2015) Knowledge, attitude and practice of nurses about standard precautions for hospital-acquired infection in teaching hospitals affiliated to Zabol University of Medical Sciences, 2014. Glob J Health Sci 8: 193-198.

11. Imad F, Ahmad A, Faeda E, Lubna H (2015) Nursing department, Arab American University, Palestine. Knowledge and practice of nursing staff towards infection control measures in the Palestinian hospitals. J Educ and Pract 6: 79-90.

12. Freahiywot AT, Eshetu HE, Workie ZW (2015) Knowledge, practice and associated factors towards prevention of surgical site Infection among nurses working in Amhara Regional State Referral Hospitals, Northwest Ethiopia. Surg Res Pract, pp: 1-6.

13. Kelemua G, Gebeyaw T (2014) Assessment of knowledge, attitude and practice of health care workers on infection prevention in Health Institute Bahir Dar City Administration. Sci J Public Health 2: 384-393. 